\title{
Implementing an aim-based outcome measure in a psychoanalytic child psychotherapy service: insights, experiences and evidence
}

\author{
Ricky Emanuel $^{1}$, Jocelyn Catty, Elizabeth Anscombe, Alison Cantle \\ and Helen Muller
}

Word count: 6,397

Abstract: 168

1. For correspondence.

Ricky Emanuel, Consultant Child \& Adolescent Psychotherapist, Child and Adolescent Mental Health Service, Royal Free Hospital, Pond Street, London NW3 2QG. Tel. 0207830 2931. < R.Emanuel@ nhs.net>

Jocelyn Catty, Child \& Adolescent Psychotherapist in Doctoral Training, Royal Free Hospital.<Jocelyn.Catty@nhs.net>

Elizabeth Anscombe, Child \& Adolescent Psychotherapist, Royal Free Hospital. <Elizabeth.Anscombe@nhs.net>

Alison Cantle, Child \& Adolescent Psychotherapist, Royal Free Hospital. <acantle@nhs.net>

Helen Muller, Child \& Family Psychotherapist, Royal Free Hospital. $<$ Helen.muller@nhs.net> 


\begin{abstract}
In this paper, we describe the use of an aim-based outcome measure used in routine outcome monitoring of child and adolescent psychotherapy within a child and adolescent mental health service. We present empirical evidence drawn from a cohort of 34 child and adolescent patients which demonstrates a statistically significant and clinically meaningful improvement in ratings of the Goal-Based Outcomes Measure. In the context of this empirical evidence, the paper aims to explore the clinical feasibility and implications of the routine use of an aim-based measure in child psychotherapy. We argue that it provides a simple and useful way of clarifying the focus of the clinical work and reflecting its progress, while also having the potential to illuminate the clinical picture by contributing an additional source of clinical information from a collaborative process with the patient, parents or both. We argue that, while there are some cases where use of the measure may be impossible or even perverse, in general it enhances rather than detracts from the clinical work.
\end{abstract}

\title{
Keywords
}

Psychoanalytic child \& adolescent psychotherapy; routine outcome monitoring; collaborative patient-rated outcome measures; aims in psychoanalytic child psychotherapy. 


\section{Background}

The Government's strategy, 'No health without mental health' (HM Government / DoH, 2011), and White Paper, 'Equity and excellence: liberating the NHS' (DoH, 2010), place outcomes of treatment at their core. An increasing emphasis on routine outcome monitoring in mental health services as an adjunct to clinical audit dates back to 2004 (DoH, 2004), with CAMHS services having been expected to adopt it from 2010 (HM Treasury, 2007). This reflects a much wider international consensus that mental health outcomes should be routinely monitored (Trauer, 2003). The UK strategies also prioritise patient-rated outcome measures, to allow patients themselves to determine whether the treatments they receive are effective.

There has been a longstanding prejudice in psychoanalytic psychotherapy about whether the real outcomes of psychotherapy are effable let alone measurable. Despite this, a significant amount of evidence has been provided empirically of the effectiveness of child and adolescent psychoanalytic psychotherapy (Midgley \& Kennedy, 2011). Yet whilst many practitioners and researchers may champion a comprehensive view of what constitutes 'evidence', as well as emphasise the importance of practice-based evidence alongside evidence-based practice, we ignore the prevailing climate in CAMHS at our peril: a climate in which evidence-based practice and its more recent counterpart, routine outcome monitoring, are increasingly emphasised, despite their pitfalls.

In this paper, we hope to demonstrate the clinical usefulness of an increasingly accepted outcome measure sanctioned by the CAMHS Outcome Research Consortium (CORC: http://www.corc.uk.net), the Goal-Based Outcomes Measure (Law, 2009). This is not an outcome study or formal audit, although we will briefly describe the conclusions that can be drawn from the data collected thus far. Rather, we are attempting to show that measuring outcomes in psychoanalytic child psychotherapy need not be an intrusive activity that gets in the way of clinical work, as indeed others have found (Baruch \& Vrouva, 2010; Urwin, 2007). We argue that it provides a simple and useful way of clarifying the focus of the clinical work and reflecting its progress, while also having the potential to illuminate the clinical picture by contributing an additional source of clinical information directly from the patient. 
We give a range of clinical examples (each of which has been disguised and anonymised), including both those where use of the measure was relatively straightforward and others where it was not, hoping to show that in situations where administering the measure is more complex, the insights to be gleaned may be particularly valuable.

\section{Routine outcome monitoring and patient-generated outcome measures}

Despite the perception that outcome monitoring is incongruent with the aims and practices of psychotherapy, there has been a long history of psychotherapy researchers investigating the research foundations for psychotherapy practice (Aveline \& Shapiro, 1995) and arguing for the complex and individual nature of outcomes in psychotherapy, in the face of demands from health-care purchasers to provide evidence of early symptom relief (Aveline, 2006). Such voices have been important in advocating that clinical relevance be prioritised in the design of research studies and outcome monitoring (ibid.) The principles of selecting measures for routine use across mental health have been long established, Slade and colleagues (1999) arguing for six 'feasibility criteria' (that any measure should be brief, simple, relevant, acceptable, available and valuable), with the acceptability of measures to clinicians being particularly emphasized (McInnes, 2006). Routine outcome monitoring in child and adolescent mental health services has been found to be acceptable to parents and carers, who have advocated that it become a more collaborative process (Moran, Kelesidi, Guglani, Davidson, \& Ford, 2011).

The well-documented reluctance of mental health clinicians to embrace outcome monitoring (Bilsker \& Goldner, 2002) may, however, relate to the rather equivocal evidence for the effectiveness of routine outcome monitoring in improving (rather than simply auditing) patient outcomes. Systematic reviews (Gilbody, House, \& Sheldon, 2001, 2002) and randomised controlled trials (RCTs) (Marshall et al., 2004) have provided negative evidence in this regard. A more recent RCT of feedback to 160 patient and staff pairs in adult mental health services found no improvement in subjective outcomes such as patient-rated unmet need and quality of life, although inpatient use and hence costs were reduced, presumably because of clinicians' increased alertness to deterioration (Slade et al., 2006). More positively, formal 
monitoring, fed back to clinicians, has been found to have a positive impact on clients in college counselling services with poor initial response (Lambert et al., 2003), with a similar result found for more disturbed adult outpatients (Hawkins, Lambert, Vermeersch, Slade, \& Tuttle, 2004).

Outcome monitoring may be achieved using any valid measure, but patient-rated outcome measures have been regarded as important tools for capturing subjective outcomes in particular (such as quality of life), although there is some evidence that they may be driven by underlying mood (Hansson, Björkman, \& Priebe, 2007). Patient-rated outcome measures used in research and audit have traditionally comprised check-lists of items selected by experts (nomothetic measures). These have the advantage of providing clinical cut-offs for caseness based on population norms, but are arguably less sensitive to individuals' distress (Ashworth, Evans, \& Clement, 2009). By contrast, measures in which the patient generates the domains or items before rating them (patient-generated or idiograhic measures) have been found to be highly sensitive to change and may thus be better at demonstrating change after talking therapies (ibid.). Using such measures, patients themselves define their own improvement and the effectiveness of the services they are receiving (Rea, 1999). Patient-generated outcome measures may also be more closely aligned to therapists' professional values and therefore more acceptable to them (Ashworth et al., 2009).

\section{Goals versus aims: psychoanalytic use of the Goal-Based Outcomes Measure}

The Goal-Based Outcomes Measure (GBOM: Law, 2009) is a patient- and cliniciangenerated, collaborative measure, designed to capture the goals or aims of treatment from the perspective of patients themselves or, for younger patients, their parents. It was designed to be a collaborative measure that patients, parents and psychotherapists or other child and adolescent mental health service (CAMHS) practitioners could use together, in order to identify appropriate and achievable treatment aims, to be used alongside more well-established core measures such as the Children's Global Assessment Scale (CGAS: Shaffer et al., 1983) and Strengths and Deifficulties Questionnaire (SDQ: Goodman, 1997; Goodman, Ford, Simmons, Gatward, \& Meltzer, 2000). Approximately three aims are identified at the outset of treatment (within the first three sessions or at the end of an asessement). These are then rated on 
a 0-10 Likert scale, where zero represents the patient not managing to deal with the identified issue at all and ten represents the issue having been fully resolved. At an appropriate review point identified by the therapist or service, the patient or parent is reminded of the original aims and these are rated again, without reference to the original ratings. The measure gives an overall score which is the mean of the (usually three) goal scores.

The name of this measure can be misleading, however, particularly to psychoanalytic psychotherapists, since it implies a goal-based treatment reminiscent of cognitivebehavioural therapy or solution-focused approaches. This implies setting treatment goals and working consciously towards achieving them within each session or the treatment as a whole. Indeed, goals-setting might seem more congruent with social cognition models of consciousness (Dijksterhuis \& Aarts, 2010). For more nondirective approaches to therapy, where the therapist follows the patient and does not instruct him/her or take an instrumental approach, the idea of working towards a goal imposed by the therapist or directing the patient's attention to goals set by them, is antithetical to their model of work. It is equally antithetical for psychoanalytic psychotherapists who seek to hold in mind Bion's (1970) injunction to eschew memory and desire so as not to be saturated with the memory of the goals set for the treatment nor with the desire to reach these goals or 'cure' the patient of his symptoms. These factors can get in the way of the therapist noticing the small changes that can occur in the patient from session to session by not allowing enough room for the patient to have changed between sessions. We have therefore chosen to implement this measure as an aim-based measure.

This distinction between aims and goals was made by Meltzer (1969). Aims are overarching attainments intended for the intervention under whose aegis the treatment progresses, whilst goals describe something more tangible to be attained and consciously pursued. Meltzer describes how the motives and wishes for coming for treatment differ between the child, the parents and in the community. He describes how the child's motives are private, wanting relief within a more short time-span, whilst the parents want reassurance and for the child to be made happy. The community, on the other hand, wants control and 'requires that expenditure on an 
individual is defensible in the face of hostile enquiry'. The latter is much more prominent today in the face of decreasing resources and increased accountability in publically funded services. Both patient (and parents where younger children are involved) and therapist need to have some ownership of the treatment aims, and the therapist should not encourage a more slavish dependence or compliance from the patient to what the therapist or parent desires these aims to be. Meltzer also cautions against the therapist yielding to external pressures that impose aims on the treatment that are not in keeping with the therapist's own values and desires (for example, the intrusive desire of parents for the therapist to get inside the mind of the child to find out what is really happening there), as well as knowledge of what is achievable in therapy. Broad aims of the treatment are therefore agreed during the assessment period and then these are put aside as the work proceeds. It is only when reviewing the therapy that the aims are reconsidered and progress against them is evaluated. This aspect of the use of the measure - setting it aside between its first use and the review point - has also been recommended with another idiographic measure, the Hopes and Expectations of Treatment Approach (HETA: Urwin, 2007) in order to discourage the therapist or others to see the exercise as imposing goals on the treatment.

An aim-based measure thus does not determine what is discussed in a session nor does it provide an external focus for the work. Instead it attempts to define operationally what has been formulated during the assessment period about why the person is coming into psychotherapy and what may be achieved by the treatment. Furthermore it does not presuppose that these aims will remain unchangeable over time. In fact, the measure discussed here allows the aims to be reformulated as the treatment progresses and new understanding or issues emerge. This gives a more coherent and objective view about why treatment may be continuing and also guards against treatment 'drift', whereby a patient might stay in psychotherapy because they have begun it or like coming or are interesting to the therapist.

\section{Setting and use of the measure}

The cases discussed here were all patients referred for child psychotherapy within an inner-London, hospital-based CAMHS service. In this service, where children are seen for child psychotherapy, concurrent parent work is usually offered by a colleague 
from the group of child psychotherapists or the wider CAMHS team. Treatment is sometimes time-limited but is more often open-ended, subject to review. It is particularly in these latter cases that the measure has helped define why treatment is continuing, as we hope to show. Use of the GBOM was introduced in 2009. With younger patients, the aims are usually identified by the parents with input from the parent worker and the child's psychotherapist; older patients will identify the aims themselves with the therapist's facilitation and the aims may, if appropriate, be shared with parents. At review meetings during the course of the therapy, the original aims are rated again. Revised aims for the therapy may also be set at review.

Data from the cohort of patients seen for child and adolescent psychotherapy and group psychotherapy were analysed, with 34 cases having Time 2 data (collected at review) available at the time of writing. Our analysis found that this cohort scored a mean improvement of 3.2 points (out of 10) on the aims measure, which reached statistical significance (see Appendix).

\section{Aim-identification in psychoanalytic child and adolescent psychotherapy}

\section{Aim-identification with adolescents}

Aim-identification in child psychotherapy is perhaps seen at its best where it helps to articulate and clarify the process of assessment and the initial phase of the therapy. This is illustrated by two cases where the adolescent patient was able to collaborate with the psychotherapist in setting aims for the therapy.

At 15, Sally was old enough to formulate the aims for her psychotherapy without parental involvement. She was referred for psychotherapy because of her temper outbursts and stubbornness in relation to the management of her medical condition. She had a progressive physical condition which affected the use of her limbs and trunk. Sally presented herself as loud and sharptongued, making jokes at her own expense and contemptuous criticisms of others.

Sally gave little indication during her assessment sessions that she could move from behind this brittle shield and allow herself to know and share her 
frustrations and fears with the psychotherapist. As part of the assessment process, towards the end of the third session, her therapist suggested they consider three aims for her psychotherapy if they were to agree to proceed. The task proved to be very helpful. It enabled Sally with the help of the therapist to formulate her worries and tell her therapist of them in a direct, straightforward manner without feeling overwhelmed by emotion. It also was a good prognostic indicator that they would be able to work together in this modality of psychotherapy. In formulating her aims (Table 1), help was only necessary in terms of wording, so that they were progressive ('to understand' and 'to try to') rather than absolute ('to stop' getting angry).

\section{- Table 1 about here -}

Ava, aged 17, was referred for weekly sessions of psychotherapy as she was being treated for anorexia nervosa. When Ava was initially seen in our department it became apparent that Ava and her single mother were rather enmeshed with each other. At any time there was an argument between them Ava felt filled up with her mother's worries, and symbolically felt her body expanded with the conflict projected into Ava. Slowly through the family therapy which prepared her for the individual psychotherapy mother and daughter began to achieve some separation between the two of them and Ava's eating pattern stabilized.

When setting the aims at the end of the three session assessment for psychotherapy, Ava described physical sensations in her body which correlated with her inability to eat, using the words 'heavy' and 'full'. The aims appeared to help Ava to make links to her relationships with her mother and her relationship with food. Ava recounted how she also felt affected in friendships, and she had realised this after an evening with a friend who had poured her heart out to her; the following morning, she had felt reluctant to eat breakfast and wanted to reduce what she was eating. Ava was able to make the connection to feeling filled up with someone else's worries and anxieties; this created some space in her mind and she was able to manage to eat what she wanted to eat. (See Table 2.)

- Table 2 about here - 


\section{Aim-identification for younger children and parents}

For younger children, it is usually necessary to involve parents in setting the aims of the therapy, even if the child is able to participate in the process too.

Richard, aged seven, was referred for child psychotherapy having been seen by a child psychiatrist in the team following referral for pulling out his hair. His parents were living together but in an acrimonious way arising from their differing parenting styles. In his assessment for psychotherapy, Richard complained of 'boredom'. It was in these 'bored' states that he resorted to pulling out his hair as he 'liked' the pain involved which relieved the 'boredom'. The psychotherapist thought the boredom was linked to states of emptiness as well as anxiety experienced around the time he was going to sleep. The anxiety seemed to connect to thoughts about the nature of his parents' relationship and what they got up to when he was in bed. Richard identified three aims (Table 3). Both parents agreed with these aims when they were discussed with them in a meeting to set up regular once-weekly psychotherapy after the assessment period.

- $\quad$ Table 3 about here -

In fact, the assumption that younger children need not be involved in identifying or rating aims was called into question in one case where the parent's aims came to feel somewhat remote from the child's.

Peter, aged eight, was referred for child psychotherapy owing to concerns about his aggression to his mother and challenging behaviour at school. His parents identified two aims for the therapy, that he should learn to express his feelings more through words and that he should understand more about boundaries. As the therapy progressed, it seemed as though Peter were determined never to bring into the therapy room any thoughts or feelings about his mother or his life outside the room. Eventually, the therapist put it to him that his parents had reported his aggressive behaviour and family therapy meetings were introduced to help Peter confront this behaviour, as an adjunct 
to his psychotherapy. His behaviour gradually improved, as his parents' ratings of the measure reflected, moving from ' 5,4 ' to ' 7,6 ' by the third review at about one year.

Although it is not uncommon for younger children to keep details of their external life out of their psychotherapy, this was particularly pronounced and troubling in Peter's case. It is an open question whether asking Peter to think about aims for his therapy, and letting him know what his mother's aims were, would have helped work with this split sooner.

\section{Aim-identification in group therapy}

Although the measure was designed to be used for setting individual treatment aims, it may be helpfully utilised in the context of group work, where each participant has the opportunity to identify and then rate their own aims for the group. The following example concerns a psychotherapy and creative group designed for six to eight girls with anorexia between the ages of 16 and 18 years old. The group was designed to provide an outlet for the girls to express thoughts and feelings and to share experiences regarding their illness, as well as to provide peer support for girls who were feeling particularly isolated. The eight-week group began with a workshop where the girls could meet and try out the group experience before committing to the next seven weeks. The two co-facilitators met the girls individually first and through discussion explored some of their underlying hopes for the group. The aim-based measure was also completed in these individual meetings, although the final evaluation was completed in the group setting.

Bea, aged 16, who was being treated for anorexia and depression, described quite straightforward aims (Table 4). When the group ended, she spoke openly about the destructive part of her personality which she felt dominated her thinking. Bea felt as though she was not so alone with some of these dark and depressed thoughts, relieved that she had shared them both visually and emotionally, and found solace through the other girls' imagery and from voicing her thoughts and finding them to be shared by the others. The changes 
shown in Table 4 show how much she felt she benefited from the group in meeting in her original aims.

- Table 4 about here -

By contrast, Tasha expressed anxiety through her aims (Table 5). At the end of the group, she wrote about finding it helpful to realise that other girls had gone through similar experiences.

- Table 5 about here -

Hana, who had experienced admissions to a paediatric inpatient ward and a specialist eating disorder unit, was keen to share with the group what part of her previous treatment had been helpful and what she felt had provoked her to continue her destructive cycle of behaviours. At the start, she wrote about the importance of having a safe place where confidentiality was respected to share her despair and hopes for the future. Her aims too were to feel more comfortable with herself by meeting other girls in the same situation and to be able to share her story with others, and her rating of these aims rose from 6 and 5 to 9 and 9 , respectively.

Overall, there was a noticeable increase in scores in the creative group, with an average increase of 2.5 points.

\section{Difficulties with aim-identification and rating}

\section{Difficulties identifying meaningful and achievable aims}

For some patients, identifying meaningful or achievable aims is extremely difficult. If it is not appropriate to ask their parents to set the aims, due to the patient's age, the psychotherapist may be faced with a patient who clearly has a need for the psychotherapy but who cannot articulate any rationale for this or own any hopes for it. In one case, a teenage girl seemed to feel blank in relation to the prospect of engaging in therapy and this was reflected when she was asked to think about aims:

Jeanette, aged 13, was referred for a psychotherapy assessment because of long episodes of screaming at home. She had a history of apnoea as an infant and 
breath-holding 'blue fits' during her latency years. In her assessment sessions, she volunteered very little information. Her typical response to the therapist's interest in her thoughts was to shrug, look blank and say 'I don't know'. She gave little indication of her feelings and seemed baffled about what they might be. It seemed as if nothing the therapist said made it possible for Jeanette to voice any feelings. What little 'information' was gathered of Jeanette's feelings was acquired by the therapist using her observations and counter-transference to suggest how Jeanette might feel.

When she was invited to draw, Jeanette checked to find out precisely what the therapist wanted. She did not appear to be anxious, but instead rather puzzlingly blank. This presentation along with the reported breath-holding and screaming suggested, amongst other possibilities, that she might have little capacity to know what her feelings were. An important aspect of the work with Jeanette would be to help her put feelings into words. Her difficulty in doing so in the assessment, however, meant that she was unable to set aims herself.

This kind of denial of any interest in the self or hope or desire for the therapy is often a case of an inability to name any emotional states. In this case, the aim of the therapy becomes one of 'developmental help' (Hurry, 1998) to enable an emotional vocabulary and literacy to develop. As an aim, this can be identified with the parents, as was the case for Jeanette.

This is not the only difficulty presented in identifying aims, however. One teenage patient, Sophie, for instance, could not identify any aims for her therapy because the very idea of this made her fear that she would fail to fulfil them. In this case, careful thinking about the distinction between treatment 'goals' and 'aims' was not sufficient to help her to feel less persecuted about the idea.

Other patients, who might be overtly quite prepared to identify and rate aims, may make a particular use of the process, reflecting their pathology rather than any clear assessment of their needs. 
Edward, a rather omnipotent and haughty eleven-year-old, wrote that one of his goals was 'self-individuation'. He presented herself in his therapy as superior and omnipotent, so the psychotherapist saw this wording as rather in keeping with how he wanted to be known. When Edward and his psychotherapist reviewed these initial goals later in the course of the therapy, he read what he had written before and spontaneously said, 'how pretentious!', telling the therapist that this was "just a fancy term for "knowing who you are"". This insight was already suggestive of some development. In a later review, revisiting the aims again at a time when Edward was more depressed, he said of all three aims, 'they're all fake; I wrote what I thought you would want'. He then wrote himself some new aims, including, 'to find out how to be real with people'.

\section{Anomalies and discrepancies in rating aims}

In some cases, identifying aims is achieved relatively easily, but the rating results show up interesting anomalies, either initially or at review. These may be helpful in reflecting the pathology of the patient. This was the case when Nancy, the mother of a premature baby, was seen for an infant mental health short-term intervention.

Baby Julia was born at 32 weeks following a difficult pregnancy and significant health concerns as a consequence for both mother and baby. The health problems had resolved by the time of Julia's six-month follow-up appointment with the paediatrician, but Nancy was tearful and anxious. They were referred to CAMHS. In the first of nine sessions, Nancy talked of often bursting into tears. She was experiencing intrusive thoughts, such as the idea that if she did not have dinner ready at a certain time then Julia would get ill. Nancy was very clear about what her worries were when setting three aims for the work (Table 6).

Nancy made good use of the sessions. She was keen to understand her behaviour and was delighted and grateful for the progress she made as a consequence of her new insights. Both Nancy and her therapist felt that it was a successful piece of work. They were therefore surprised and rather disappointed to see the comparison with Nancy's scores at review, which had barely increased from '7, 6, 
6' (in fact, one had gone down). They realised that Nancy's original scores had been too high and should have been questioned by the therapist during the assessment, as they had not accurately reflected her state of mind. As the work progressed, it became apparent that it was characteristic of Nancy to present a more optimistic front than she actually felt. Out of interest, at a later review, the therapist asked her how she thought she should have scored herself originally. Nancy thought it should have been much lower, at ' $4,3,3$ '.

- Table 6 about here -

This example demonstrates that the way patients use the aim-setting exercise reflects their individual, clinical picture, as we might expect. In this case, the mother's tendency to present a more optimistic picture than she really felt significantly coloured her baseline scoring of the aims measure. This reinforces the message that the setting and scoring of aims needs to be a collaborative task. If psychotherapists do not make use of their clinical understanding of the patient when agreeing upon the aims and scores, the outcomes may not accurately reflect the progress, or otherwise, of the treatment.

The collaborative nature of the exercise, however, where it involves both child and parent(s), can itself provide some difficulties. This was the case with the case of Richard, presented above, when he and his parents chose to introduce new aims at the review.

At review four months into the treatment, there had been improvements in all the scores. Richard's parents again concurred when the scores were discussed with them. In the course of the work with Richard, it became clear that he had real difficulties trusting other people as well as himself. We agreed at review to add this as new aim and to include the hair-pulling aim again, since he and his parents were anxious that it could return. Richard himself could not identify a new third aim but his parents wanted us to be aware that Richard had serious tantrums when he could not get his own way and they wanted to include this issue as a new aim. The difficulty here was that Richard did not agree with this view of him nor recognise that he had a problem in this area. Consequently when Richard came to 
score the new aim, he rated his own new aim about trust at the mid-point (5 out of 10), showing no change between time-points as he did not think this had improved, but rated his parents' suggested aim about tantrums as 9 the first time and 10 the second time (indicating that he regarded it as barely an issue at all). By contrast, his parents disagreed with each other about the 'trust' goal, his mother agreeing with Richard while his father disagreed that it was a problem; their T2 ratings, not surprisingly, showed a contrast between 5 (mother) and 8 (father). For the 'tantrums' goal they had introduced, they agreed with each other, but not with Richard, that she was still a 7.5 at the second rating. (Table 3.)

This case raises interesting issues about who should score the measure, as the child's view and the parents views clearly differed here, as indeed as is often the case for measures that are rated by both child and parent (De Los Reyes \& Kazdin, 2005). Even though there were differences, however, the measure allowed the psychotherapist to bring into the therapy the parents' concerns about anger and tantrums, albeit that these issues were not recognised by the child. The measure was also dynamic enough to allow the possibility of introducing the newly identified issue of trust, which had arisen from within the psychotherapy itself, to become a focus of the therapy and to feature among its desired outcomes.

\section{Perverse aim-setting}

One of the pitfalls of setting and rating aims is that, without sufficient collaboration or intervention from the psychotherapist, the patient may identify aims for his/her therapy that are perverse. Such aims might be too idealised and unachievable or, conversely, too easily achievable; or they might identify aims that would be inimical to the work of psychotherapy, such as where a patient suffering from an eating disorder might wish to set an aim of losing weight.

Petra, a 17-year-old girl, saw herself as psychotic and paranoid, although the psychiatrists who assessed her did not agree. In her therapy, she set two aims which appeared to be reasonable: 'to feel less persecuted about people' and 'to feel more real'. Petra scored both these aims at zero initially. In retrospect, it seemed as though her rating of these apparently reasonable aims had been driven 
by her wish to assert her belief that she had a psychotic disorder. That this was problematic became clear at review. By now, she was so angry that her view of herself was not confirmed by the wider CAMHS team that she displayed a 'flight to health', wanting to stop all contact with CAMHS and so maintaining that everything was 'totally fine' when in fact it was not. She therefore rated both aims at 10 (a perfect cure).

Petra's aims were only useful in consolidating the team's view of her as having an emerging personality disorder; they were in no way useful as an outcome measure or as a collaborative clinical process with her. Since she tended to report that she was worse in every session, she would not have welcomed any demonstrable improvement in her mental state, being so wedded to her identity as a long-term, hopeless psychiatric patient.

\section{Where aim-identification is inappropriate}

Some patients who are very depressed, psychotic or fragmented do not have the capacity to think about, let alone formulate, aims of the therapy, even in collaboration with the therapist. In one such case, a 15-year-old adolescent girl with pervasive refusal syndrome referred for psychotherapy was mostly mute but would communicate with the tiniest nods or shakes of her head. She readily engaged in the psychotherapy process, occasionally talking in strangulated whispers or drawing compressed and tiny figures. The psychotherapy commenced whilst she was an inpatient on the paediatric ward. Whilst the therapist might have been able to formulate broad aims of the psychotherapy (such as to help her feel that her emotions could be named and given some meaning), it did not feel appropriate to get someone in such a broken-down state to agree to or try to score such aims. We have always left it to clinical judgement whether the outcome measures are used as they can in these circumstances feel intrusive and inappropriate. At a later time in the therapy when things have stabilised and therapy continues, aims may be identified for ongoing work. 


\section{Discussion and implications}

As the clinical examples given here show, using an aim-based measure in child and adolescent psychoanalytic psychotherapy is more straightforward in some situations than others. Yet it invariably reflects the complexities of the clinical situation, in ways that may be illuminating. For patients like Sally, who was struggling with temper outbursts and stubbornness in relation to her medical condition, using the aims measure may help to crystallise the work of the assessment or early part of the psychotherapy process; later in the process, for patients such as Richard, who had been pulling out his hair, aims may be revised helpfully at review and discrepancies between the parents' and child's views may be highlighted, if not resolved. As we have tried to demonstrate, difficulties emerging during this exercise may actually enhance our clinical understanding by providing an additional source of information that might not have been elicited as soon, or as clearly, through the usual psychotherapeutic process. Aim-identification may thus be problematic or give rise to anomalous results, as the rating may be skewed by the patient's need for approval (to say what they think the therapist wants to hear, like Edward) or by the need to present a brave face (like Nancy), but understanding what has happened may enrich the clinical picture. It not only helps us communicate the clinical picture to others, but enhances the psychotherapeutic process, as has been found of HETA (Urwin, 2007).

Using an aim-based measure thus provides the psychotherapist with a means of triangulating information about the patient, not only with information from other sources (from parents, or, as is usual practice in a multidisciplinary service, from other professional perspectives) but with this different type of outcome information gathered in a collaborative process with the patient. Comparably, the changing scores provided over time when the measure is re-rated subsequently also provide a different sort of evidence, quantitative evidence, of their progress. In our case, the overall improvement of just over three points by the first review was statistically significant and we would also regard this as clinically meaningful.

This triangulation of information and understanding, naturally, works both ways. Clinical insight is often necessary to help understand the aims and changes in ratings, as our examples of Nancy and Edward in particular demonstrate. This has 
implications for outcome monitoring per se, suggesting that clinical insights may be needed to supplement quantitative data that could be misleading taken in isolation. This might be difficult to achieve where outcomes are monitored in aggregate. Similarly, details of the individual patient's trajectory, including revision of aims along the way, would be unlikely to be captured in any large-scale outcome monitoring exercise and would only be picked up by extremely detailed audit. Using clinical insight would, however, be possible and important where outcomes are fed back to clinicians, parents or patients. In fact, while the evidence about feeding back outcomes has been somewhat equivocal (as described above), the measure we have discussed is one that builds feedback into the process in an integral way, provided that the patient is reminded of their original rating once they have re-rated the aims.

Despite these caveats, our experience of using the Goal-Based Outcomes Measure suggests that it would be a useful addition to outcome studies in child psychotherapy, provided a thorough protocol about its use, consistent with other core measures, could be agreed on. (For instance, although our timing was guided by the natural review process in each therapy, in fact our mean time between Time 1 and Time 2, five months, was consistent with the protocol for the SDQ.) The implications of its emphasis on collaboration between patient and therapist have not yet been explored, in contrast to, for instance, the separate analysis of parents' and therapists' views in the comparable measure HETA (Urwin, 2007). Our paper, however, may stand as some evidence about its feasibility for use both with patients and their parents in child psychotherapy. In fact, our experience suggests that it meets Slade and colleagues' (1999) criteria that an outcome monitoring measure be brief, simple, relevant, available and, we would argue, relevant and acceptable - at least to child psychotherapists. Although we have used it with a relatively small sample of patients, we hope we have demonstrated that a measure of this kind can achieve the twin aims of providing meaningful quantitative evidence for the purposes of outcome monitoring and generating additional clinical insights through the collaborative process it demands of patient, parent and psychotherapist. 


\section{Appendix: Empirical evidence}

\section{Methods}

The GBOM was administered at the end of the assessment process or start of psychotherapy, as described above (T1). Descriptive statistics on age at T1, gender, type of psychotherapy (individual or group) and rater of the measure are provided for the whole cohort as at 1 December 2011. The measure was rated at each review point. Time 2 (T2) data were analysed for those patients who by 1 December 2012 had T2 data collected between one and 12 months after T1. Descriptive statistics on this cohort are also provided below. A sample size calculation based on T1 data suggested that 26 patients would be needed to detect a one-point difference in the GBOM, with $80 \%$ power. The difference in the mean aims rating between $\mathrm{T} 1$ and $\mathrm{T} 2$ was calculated using paired t-tests. A sensitivity analysis was performed to determine the contribution of the patients seen in group therapy, analysing the difference in mean aims data with and without this group. All data were analysed using SPSS for Windows (version 20.0).

\section{Results}

Data from 47 patients or parents were collected, of whom 40 attended individual psychotherapy only, six attended group psychotherapy only and one attended both. Ten patients were male and the mean age of the patients was 12 . The measure was rated by the patient (collaboratively with the psychotherapist) in 30 cases and by the parent in the remaining 17. T2 data (collected at the first review) were available for 36 cases and T3 data (second review) for eight cases (not analysed here). Four patients chose to revise their goals at review.

The 34 patients whose data met criteria for analysis (T2 data collected between 1 and 12 months after T1) had a mean age of 12. (Two patients were excluded, one of whom had re-rated the aims after less than one month and one after 19 months.) For the patient who had attended both individual and group therapy, her group aims data were excluded. Eight patients were male. The measure was rated by the patient in 23 cases and by a parent or parents in 11 cases. The mean time between $\mathrm{T} 1$ and $\mathrm{T} 2$ was mean of 4.7 months. The cohort scored a mean improvement of 3.2 points (out of ten) on the GBOM and this was statistically significant. (Table 7.) 
The sensitivity analysis suggested that the inclusion of the group of six patients seen in group therapy inflated the overall mean difference by half a point (mean difference 2.7 without group data, compared to 3.2 with group data), but did not affect the statistical significance of this finding.

- $\quad$ Table 7 about here -

\section{Declaration of interest}

We declare that we have no conflict of interest.

\section{Acknowledgements}

We are grateful to Nick Midgley, Anna Freud Centre, for his helpful comments on this paper. 


\section{References}

Ashworth, M., Evans, C., \& Clement, S. (2009). Measuring psychological outcomes after cognitive behaviour therapy in primary case: A comparison between a new patient-generated measure 'PSYCHLOPS' (Psychological Outcome Profiles) and 'HADS' (Hospital Anxiety and Depression Scale). Journal of Mental Health, 18(2), 169-177.

Aveline, M. (2006). Commentary on 'Using clinical outcomes in routine evaluation'. European Journal of Psychotherapy \& Counselling, 8(2), 227-234.

Aveline, M., \& Shapiro, D. A. (Eds.) (1995). Research foundations for psychotherapy practice. Chichester: Wiley.

Baruch, G., \& Vrouva, I. (2010). Collecting routine outcome data in a psychotherapy clinic for young people: Findings from an ongoing study. Child and Adolescent Mental Health, 15(1), 30-36.

Bilsker, D., \& Goldner, E.M. (2002). Routine outcome measurement by mental health-care providers: Is it worth doing? Lancet, 360, 1689-1690.

Bion, W.R. (1970). Attention and interpretation: A scientific approach to insight in psycho-analysis and groups. London: Tavistock.

De Los Reyes, A, \& Kazdin, A. E. (2005). Informant discrepancies in the assessment of childhood psychopathology: A critical review, theoretical framework, and recommendations for further study. Psychological Bulletin, 131(4), 483-509.

Department of Health (2004). Organising and delivering psychological therapies. London: Department of Health.

Department of Health (2010). Equity and excellence: Liberating the NHS. London: Department of Health.

Dijksterhuis, A., \& Aarts, H. (2010). Goals, attention, and (un)consciousness. Annual Review of Psychology, 61, 467-490.

Gilbody, S.M., House, A.O., \& Sheldon, T.A. (2001). Routine administered questionnaires for depression and anxiety: systematic review. BMJ, 322, 406409.

Gilbody, S.M., House, A.O., \& Sheldon, T.A. (2002). Routine administration of Health Related Quality of Life (HRQoL) and needs assessment measures to improve psychological outcome - A systematic review. Psychological Medicine, 32(8), 1345-1356. 
Goodman, R. (1997). The Strengths and Difficulties Questionnaire: A research note. Journal of Child Psychology and Psychiatry, 38, 581-586.

Goodman, R., Ford, T., Simmons, H., Gatward, R., \& Meltzer, H. (2000). Using the Strengths and Difficulties Questionnaire (SDQ) to screen for child psychiatric disorders in a community sample. British Journal of Psychiatry, 177, 534-539.

HM Treasury (2007). Public service level agreement 12. London: HM Government.

HM Government / Department of Health (2011). No health without mental health: A cross-government mental health outcomes strategy for people of all ages. London: HM Government / Department of Health.

Hansson, L., Björkman, T., \& Priebe, S. (2007). Are important patient-rated outcomes in community mental health care explained by only one factor? Acta Psychiatrica Scandinavica, 116, 113-118.

Hawkins, E. J., Lambert, M. J., Vermeersch, D. A., Slade, K., \& Tuttle, K. C. (2004). The therapeutic effects of providing patient progress information to therapists and patients. Psychotherapy Research, 14(3), 308-327.

Hurry, A. (Ed.) (1998). Psychoanalysis and developmental therapy. Monograph of Psychoanalysis Unit, University of London and Anna Freud Centre; London: Karnac Books.

Lambert, M. J., Whipple, J. L., Hawkins, E. J., Vermeersch, D. A., Nielsen, S. L., \& Smart, D. W. (2003). Is it time for clinicians to routinely track patient outcome? A meta-analysis. Clinical Psychology: Science and Practice, 10(3), 288-301.

Law, D. (2009). Goal Based Outcomes (GBOs): Some useful information. London: CAMHS Outcome Research Consortium.

Marshall, M., Lockwood, A., Green, G. Zajak-Roles, C., Roberts, C., \& Harrison, G. (2004). Systematic assessments of need and care planning in severe mental illness. Cluster randomised controlled trial. British Journal of Psychiatry, 185, 163-168.

McInnes, B. (2006). Management at a crossroads: The service management challenge of implementing routine evaluation and performance management in psychological therapy and counselling services. European Journal of Psychotherapy \& Counselling, 8(2), 163-176. 
Meltzer, D. (1969). The relation of aims to methodology in the treatment of children. Journal of Child Psychotherapy, 2(3), 57-61.

Midgley, N., \& Kennedy, E. (2011). Psychodynamic psychotherapy for children and adolescents: A critical review of the evidence base. Journal of Child Psychotherapy, 37(3), 232-260.

Moran, P., Kelesidi, K., Guglani, S., Davidson, S., \& Ford, t. (2011). What do parents and carers think about routine outcome measures and their use? A focus group study of CAMHS attenders. Clinical Child Psychology \& Psychiatry, online 24 February.

Rea, D. (1999). Towards routine user assessment of mental health quality performance. International Journal of Health Care Quality Assurance, 12, 169-176.

Shaffer, D., Gould, M.S., Brasic, J., Ambrosini, P., Fisher, P., Bird, H., \& Aluwahlia, S. (1983). A Children's Global Assessment Scale (CGAS). Archives of General Psychiatry, 40(11), 1228-1231.

Slade, M., McCrone, P., Kuipers, E., Leese, M., Cahill, S., Parabiaghi, A., Priebe, S., \& Thornicroft, G. (2006). Use of standardised outcome measures in adult mental health services: Randomised clinical trial. British Journal of Psychiatry, 189, 330-336.

Trauer, T. (2003). Routine outcome measurement by mental health-care providers. Lancet, 361, 1137.

Urwin, C. (2007). Revisiting 'What works for whom?': A qualitative framework for evaluating clinical effectiveness in child psychotherapy. Journal of Child Psychotherapy, 33(2), 134-160. 
Table 1: Sally's Aims

\begin{tabular}{|l|lcc|}
\hline \multicolumn{2}{|l}{} & T1 & T2 \\
\hline 1 & $\begin{array}{l}\text { To get less angry and to understand what makes me } \\
\text { angry. }\end{array}$ & 3 & 6 \\
3 & $\begin{array}{l}\text { To try to accept my diagnosis and what it means for me. } \\
\text { To worry less about what things are like for me and how }\end{array}$ & 2 & 6 \\
& they will be in the future. & 6 & \\
\hline
\end{tabular}


Table 2: Ava's Aims

\begin{tabular}{|l|lcc|}
\hline \multicolumn{2}{|l}{} & T1 & T2 \\
\hline 3. & $\begin{array}{l}\text { To feel that I have a space where I can talk about the } \\
\text { heaviness in my chest and the full-up feelings. }\end{array}$ & 4 & 6 \\
4. & $\begin{array}{l}\text { To begin to understand the patterns about my thoughts } \\
\text { and feelings around not wanting to eat. }\end{array}$ & 8 & 9 \\
To thinks about why I'm finding it hard to socialize. & 4 & 6 \\
\hline
\end{tabular}


Table 3: Richard's Aims (Richard's scoring)

\begin{tabular}{|ll|ccc|}
\hline \multicolumn{2}{|c|}{} & T1 & T2 & T3 \\
\hline 1 & $\begin{array}{l}\text { To prevent hair-pulling coming back. } \\
2\end{array}$ & 4 & 7 & 8.5 \\
& $\begin{array}{l}\text { To try to have less difficulty getting to } \\
\text { sleep }\end{array}$ & 3 & 9 & 8.5 \\
$3 \quad \begin{array}{l}\text { To find better ways of managing } \\
\text { boredom }\end{array}$ & 5 & 9 & 10 \\
New aims introduced at T2 & & & \\
$4 \quad \begin{array}{l}\text { To feel more trusting of myself and } \\
\text { others more. } \\
\text { To understand why I get into rages. }\end{array}$ & - & 5 & 10 \\
\hline
\end{tabular}


Table 4: Bea's Aims

\begin{tabular}{|ll|cc|}
\hline & & T1 & T2 \\
& & 1 & 9 \\
2 & $\begin{array}{l}\text { To feel less anxious about meeting and speaking with } \\
\text { other girls being treated for anorexia and depression. }\end{array}$ & & \\
& $\begin{array}{l}\text { To share my difficulties about eating in the hope of } \\
\text { finding more support. }\end{array}$ & 7 & \\
3 & To stop feeling so lonely and depressed. & 3 & 7 \\
\hline
\end{tabular}


Table 5: Tasha's Aims

\begin{tabular}{|ll|cc|}
\hline & & T1 & T2 \\
\hline 1 & To learn to see other anorexic girls in a less envious and & 2 & 8 \\
& competitive way. & & \\
2 & To express my frustration with food more creatively. & 1 & 7 \\
3 & To feel more comfortable with others in the same & 2 & 10 \\
& situation. & & \\
\hline
\end{tabular}


Table 6: Nancy's Aims

\begin{tabular}{|ll|rrr|}
\hline & & T1 & T2 & T3 \\
\hline 1 & To believe I can be a good mother & 7 & 7 & 8 \\
2 & To worry less about Julia's health and safety. & 6 & 6 & 8 \\
3 & $\begin{array}{l}\text { To feel less troubled by what happened with my } \\
\text { pregnancy Julia's premature birth. }\end{array}$ & 6 & 5 & 7 \\
\end{tabular}


Table 7: Empirical findings

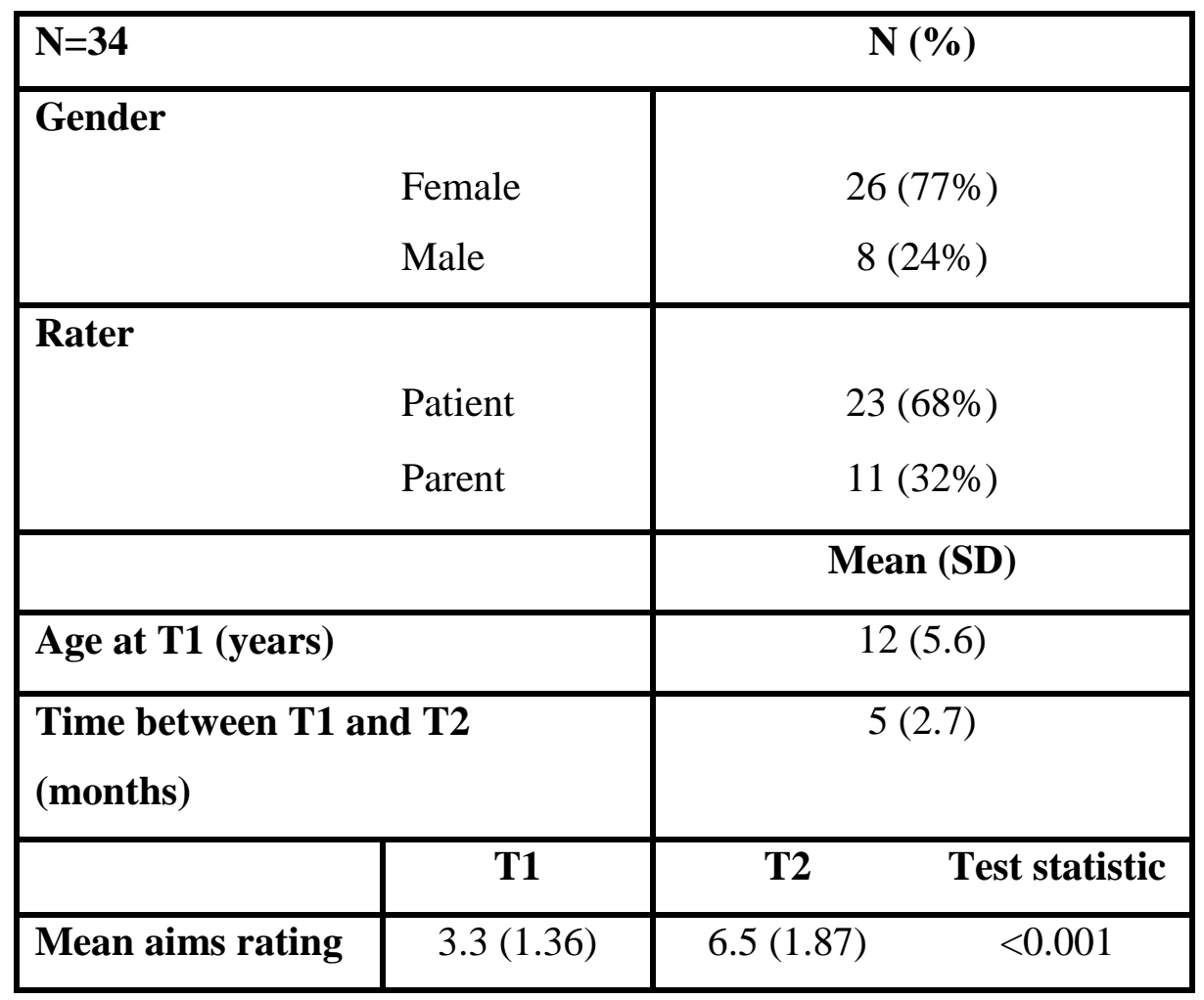

